Original Research Paper

\title{
Experimental Study of Particle Emissions from a Modern 5 kW Pellet Stove
}

\author{
${ }^{1}$ Igor V. Dyakov, ${ }^{1}$ Benjamin Bergmans, ${ }^{2}$ Svend Bram, ${ }^{3}$ Jacques De Ruyck and ${ }^{3}$ Francesco Contino \\ ${ }^{1}$ Cellule Emissions Atmosphériques, Institut Scientifique de Service Public (ISSeP), rue du Chéra 200, 4000 Liège, Belgium \\ ${ }^{2}$ Department of Engineering Technology, Vrije Universiteit Brussel (VUB), Pleinlaan 2, 1050 Brussels, Belgium \\ ${ }^{3}$ Department of Mechanical Engineering, Vrije Universiteit Brussel (VUB), Pleinlaan 2, 1050 Brussels, Belgium
}

Article history

Received: 2016-10-01

Revised: 21-10-2016

Accepted: 24-10-2016

Corresponding Author:

Igor V. Dyakov

Cellule Emissions

Atmosphériques, Institut

Scientifique de Service Public, rue du Chéra 200, 4000 Liège,

Belgium

Email: i.dyakov@issep.be

\begin{abstract}
This work is dedicated to the determination of the particle emission from a commercially available bottom feed $5 \mathrm{~kW}$ pellet stove. Two-stage dilution was applied to provide the operational stability and conditioning of the sample. The analysis of particle emission was performed by means of the Electrical Low Pressure Impactor with 14 stages, able to separate particles from 0.006 to $10 \mu \mathrm{m}$. Measurements were carried out for several runs with nominal and part load regimes respectively at 5 and $2.5 \mathrm{~kW}$. The study is focusing on the particle concentrations and their number size distributions as these factors have an important impact on atmospheric pollution and human health. The emission factors from different combustion cycles were in a range from $3.07 \times 10^{14}$ to $2.44 \times 10^{15}$ particles per $\mathrm{kg}$ (from $1.97 \times 10^{13}$ to $1.57 \times 10^{14}$ particles per MJ). The majority of measured particles were smaller than $1 \mu \mathrm{m}$. The particle distribution varied in different phases of combustion. The emission factors from different combustion cycles with included burnout phases were in a range from $2.53 \times 10^{14}$ to $2.67 \times 10^{15}$ particles per kg (from $1.62 \times 10^{13}$ to $1.71 \times 10^{14}$ particles per MJ).
\end{abstract}

Keywords: Particulate Matter, Biomass Combustion, Pellet Stoves

\section{Introduction}

The use of modern biomass combustion devices for domestic heating purposes-and consequently their market expansion-has been increasing the past decades with further perspectives as a renewable energy conversion technology. This includes small scale installations such as pellet stoves that are used for additional thermal comfort or as a single source of heat. Wood pellets consumed by these devices are quite common and are also used for various appliances because of their rather high energy density, easy storage, transportability and availability. Due to the high level of technological maturity of these devices, their low emissions and their low costs of ownership, they happen to be competitive to traditional $\log$ wood stoves for residential applications. However, particulate matter emitted during the combustion of wood pellet is one of constituents of the flue gases leaving the stove and are considered as a source of air pollution. The EU standards characterize the particle emissions in terms of mass concentration (EN 13284-1, 2002), however, current research demonstrates that other parameters, such as the number and size of particles, are essential when assessing the impact on the environment and human health (WHO, 2006; Bølling et al., 2009).

The objective of this work was to measure and characterize the particle emissions from the state-of theart pellet stove introduced on the Belgian market.

\section{Experimental}

The measurement of emissions from a bottom feed pellet stove with a nominal heat output of $5 \mathrm{~kW}$ were carried out. The screw mechanism with a preset rotation rate conveyed the wood pellets from the storage reservoir, integrated into the installation, to the burner outlet. The controlled fan provided supply of primary and secondary air into the combustion chamber. The flue gases leaving the combustion chamber were passing through a heat exchanger and vented into the thermally insulated metal stack. A cleaning routine of the combustion chamber was performed during one minute every $40 \mathrm{~min}$ by removing the congregated ash on the burner grid, while the fuel supply rate was decreased and the air flow rate increased. To determine the fuel consumption rate, the tested equipment was installed on a scale, allowing for the continuous registration of the change in mass. The particle 
measurements were conducted along with the gas emission tests in accordance with the EN 14785 standard for residential space heating appliances fired by wood pellets (EN-14785, 2006). The concentration of the flue gases sampled from the stack were continuously monitored by a Siemens Ultramat 6 gas analyser with the dry sample technique. The temperature in the stack were measured by K-type thermocouples. The particulate matter emissions were sampled in the stack by a stainless steel probe connected to a Venacontra two stage dilution system consisted of a porous tube and ejector dilutors to decrease the temperature and particle concentration of the raw sample (Sippula, 2010). The Dilution Ratio (DR) was determined as a ratio of carbon dioxide concentrations in the raw and diluted samples. The concentration of carbon dioxide in the ambient air was preliminary subtracted from each part of the fractions. The diluted $\mathrm{CO}_{2}$ concentration was measured continuously by a Vaisala Carbocap GMP 343 analyser with the dry sample technique. The DR in the tests varied between 23 and 42 . The diluted gas flow was directed to a measuring device, an Electrical Low Pressure Impact or (ELPI + ) from Dekati Ltd. By means of 14 separating stages, the device measures in real-time the particle mass and size concentrations as well as their size distributions in a range of aerodynamic diameters from 0.006 to $10 \mu \mathrm{m}$. Since the majority of particles in the emission smoke are less than 1 $\mu \mathrm{m}$ and their aerodynamic properties are similar to those of the gaseous substance, isokinetic sampling was not performed. Commercially available soft wood pellets were fired. Their properties are shown in Table 1.

\section{Results and Discussion}

The construction of the pellet stove allows changing the air and fuel supply rates by varying respectively the fan and feed screw rotation speeds. Two operational regimes of the fuel supply rate were tested: A nominal regime at $5 \mathrm{~kW}$ and a part load regime at $2.5 \mathrm{~kW}$. For the nominal fuel load, the two different regimes of air supply were studied. The measurement of gaseous and particle emissions as well as the temperature in the stack were carried out for both air supply regimes. Particle emission factors estimated from measurements, together with relevant equipment settings and air excess values $(\lambda)$ are represented in Table 2.

The study focused on the evaluation of the emissions during the different phases of combustion. Those phases can be seen in Fig. 1 for the time series records of Test 5 for the total particle concentrations, the concentrations of gaseous emissions and the temperature in the stack.

A starting phase usually took approximately $1 \mathrm{~h}$ including the lightening of the flame and the warm-up of the combustion device, accompanied by a constant increase in temperature and variations in the gaseous emissions. The particle number concentration distributions of this stage (shown in Fig. 2) demonstrate significant variations, perhaps due to permanent changes and perturbations of the combustion conditions and can be related to the emissions of carbonaceous material as soot and condensable organics (Boman et al., 2011). The total particle emission during the starting phase is at about the same level as in the combustion phase. The concentrations of $\mathrm{CO}$ are expectedly higher, in a range between 900 and $2500 \mathrm{mg} / \mathrm{Nm}^{3}$ (at $13 \% \mathrm{O}_{2}$ ) while the combustion chamber is heating up as compared to the range between 50 and $1500 \mathrm{mg} / \mathrm{Nm}^{3}$ (at $13 \% \mathrm{O}_{2}$ ) during stationary combustion.

The combustion regime was considered as the stationary phase, e.g., when the carbon monoxide concentration was relatively low and stable. The device operation in this regime usually lasted several hours, Fig. 1. The observed number concentration distributions are bimodal, Fig. 3. The mode of fine particles is dominant with a maximum in the vicinity of 70 and $120 \mathrm{~nm}$. The concentrations of particles in the coarse mode, with a size larger than $1 \mu \mathrm{m}$, are significantly lower and steadily decreasing for larger diameters without showing a maximum.

Table 1. Properties of soft wood pellets used as fuel

\begin{tabular}{|c|c|c|c|c|c|c|c|c|}
\hline \multicolumn{3}{|c|}{ Ultimate analysis } & \multicolumn{2}{|c|}{ Proximate analysis } & \multirow{2}{*}{$\begin{array}{l}\mathrm{LHV} \text { ar., } \\
\mathrm{MJ} / \mathrm{kg}\end{array}$} & \multirow{2}{*}{$\begin{array}{l}\text { Length, } \\
\mathrm{mm}\end{array}$} & \multirow{2}{*}{$\begin{array}{l}\text { Diameter, } \\
\mathrm{mm}\end{array}$} & \multirow{2}{*}{$\begin{array}{l}\text { Density, } \\
\mathrm{kg} / \mathrm{m}^{3}\end{array}$} \\
\hline $\mathrm{C}, \mathrm{wt} \%$ & $\mathrm{H}$, wt \% & $\mathrm{O}, \mathrm{wt} \%$ & Ash, wt \% & Moisture, $\%$ & & & & \\
\hline 49.1 & 5.8 & 44.8 & 0.3 & 8.6 & 15.61 & $<45$ & 6 & 675 \\
\hline
\end{tabular}

Table 2. Particle emission factors and characteristics of the tests combustion conditions

\begin{tabular}{|c|c|c|c|c|c|c|c|c|}
\hline \multirow[b]{2}{*}{$\begin{array}{l}\text { Test } \\
\text { no }\end{array}$} & \multicolumn{2}{|c|}{ Without burnout } & \multicolumn{2}{|c|}{ With burnout } & \multicolumn{3}{|c|}{ Fan and feed screw settings } & \multirow[b]{2}{*}{$\begin{array}{l}\text { Air } \\
\text { Excess, } \lambda\end{array}$} \\
\hline & $\begin{array}{l}\text { Particles } \\
\text { per kg }\end{array}$ & $\begin{array}{l}\text { Particles } \\
\text { per MJ }\end{array}$ & $\begin{array}{l}\text { Particles } \\
\text { per kg }\end{array}$ & $\begin{array}{l}\text { Particles } \\
\text { per MJ }\end{array}$ & $\begin{array}{l}\text { Fan speed } \\
\text { rpm }\end{array}$ & $\begin{array}{l}\text { Screw speed, } \\
\text { rpm }\end{array}$ & $\begin{array}{l}\text { Screw rotation, } \\
\text { sec per } 6 \mathrm{sec}\end{array}$ & \\
\hline 1 & $2.09 \times 10^{15}$ & $1.34 \times 10^{14}$ & $2.67 \times 10^{15}$ & $1.71 \times 10^{14}$ & 1250 & 2.0 & 3.2 & 2.7 \\
\hline 2 & $2.44 \times 10^{15}$ & $1.57 \times 10^{14}$ & $1.91 \times 10^{15}$ & $1.22 \times 10^{14}$ & 1250 & 2.0 & 3.2 & 2.9 \\
\hline 3 & $1.74 \times 10^{15}$ & $1.11 \times 10^{14}$ & $1.07 \times 10^{15}$ & $6.88 \times 10^{13}$ & 1250 & 2.0 & 3.2 & 2.5 \\
\hline 4 & $3.90 \times 10^{14}$ & $2.50 \times 10^{13}$ & $3.95 \times 10^{14}$ & $2.53 \times 10^{13}$ & 1400 & 2.5 & 3.2 & 2.1 \\
\hline 5 & $3.07 \times 10^{14}$ & $1.97 \times 10^{13}$ & $2.53 \times 10^{14}$ & $1.62 \times 10^{13}$ & 1400 & 2.5 & 3.2 & 2.2 \\
\hline 6 & $4.86 \times 10^{14}$ & $3.12 \times 10^{13}$ & $3.61 \times 10^{14}$ & $2.32 \times 10^{13}$ & 0900 & 2.0 & 1.6 & 4.8 \\
\hline 7 & $4.45 \times 10^{14}$ & $2.85 \times 10^{13}$ & $3.51 \times 10^{14}$ & $2.25 \times 10^{13}$ & 0750 & 2.0 & 1.6 & 4.6 \\
\hline
\end{tabular}



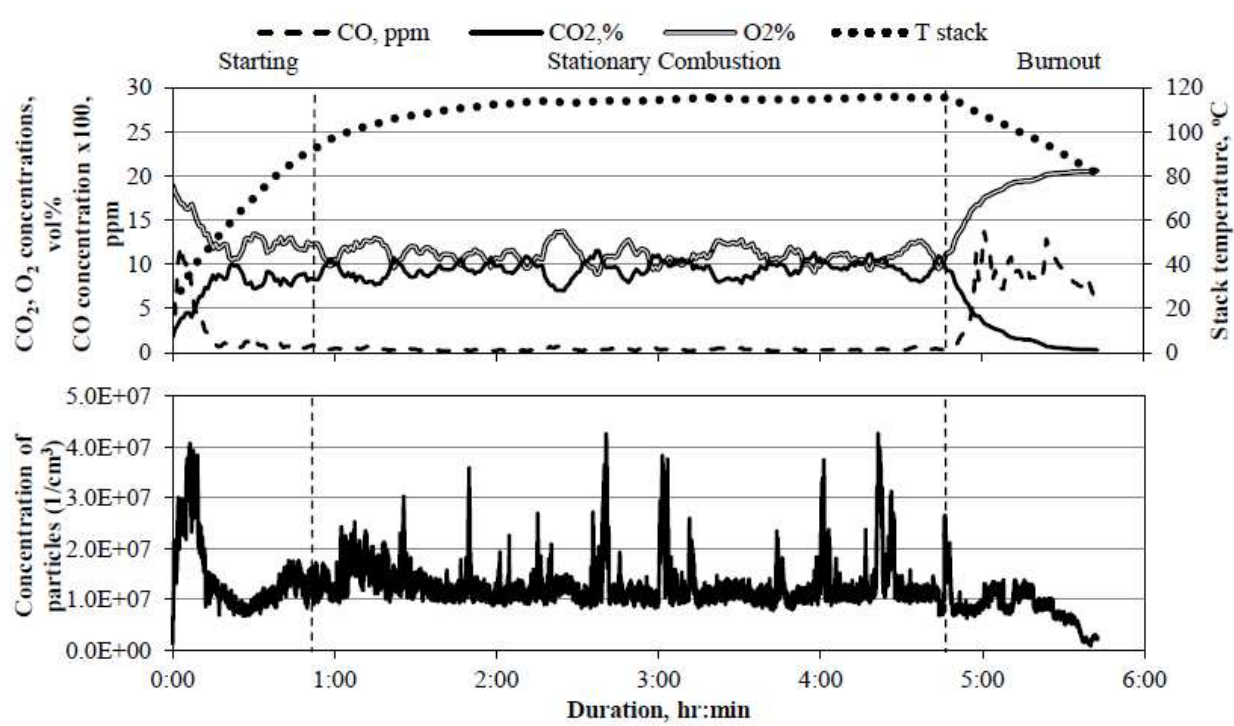

Fig. 1. Time series of particle number concentrations, gaseous emissions and flue gas temperature during the Test 5

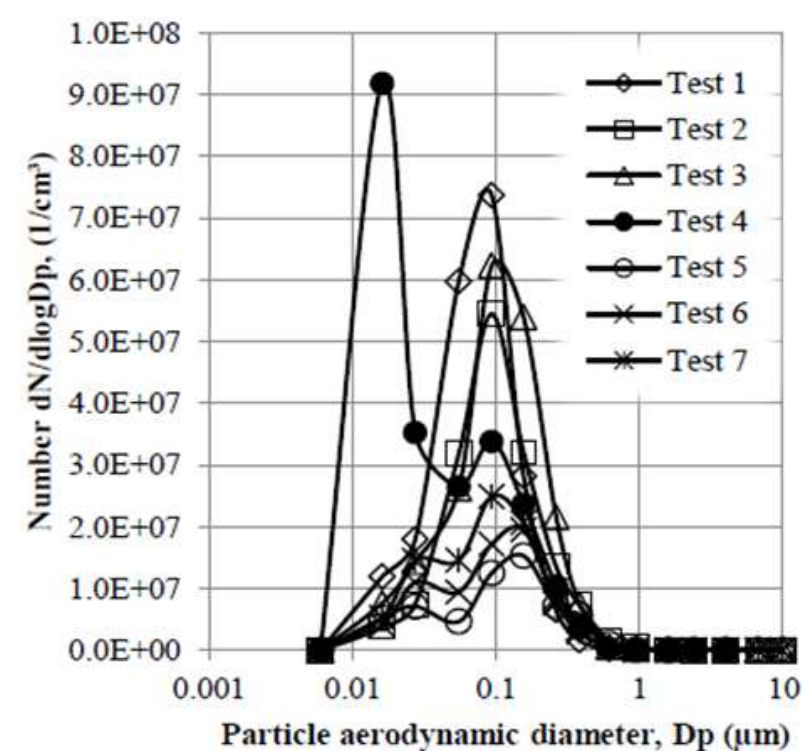

Fig. 2. Number size distribution obtained from startup phase of different tests

The total particle concentrations represented for the combustion phase agree well with the results obtained by (Boman et al., 2011; Bari et al., 2011). Tissari et al. (2003) studying devices with a similar power load. Tests 1 to 5 correspond to the nominal operational regime of the stove. Tests 1 to 3 were carried out with the excess air in the range of 2.7 and 2.9 and tests 4 and 5 with the excess air in the range of 2.1 and 2.2. Adjusting the primary and secondary air distribution in the combustion chamber is resulting in a slight decrease of concentration of particles from approximately $9 \times 10^{7}$ to $1 \times 10^{7} \mathrm{~cm}^{-3}$.

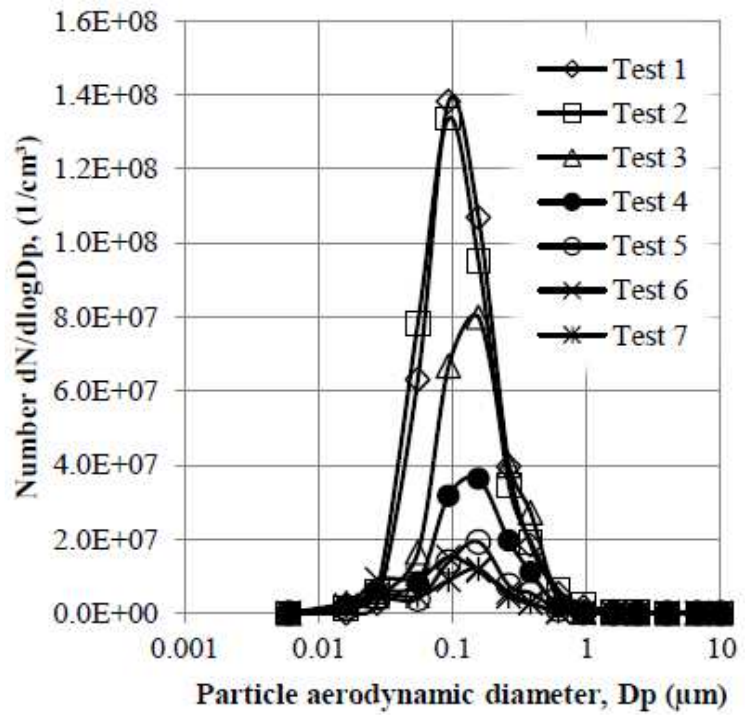

Fig. 3. Number size distribution obtained from combustion phase of different tests

It can be explained by the temperature elevation, which decelerates the condensation and agglomeration process leading to the formation of particles and by enhancing the combustion efficiency with increased burning rate (Sippula et al., 2007) between those regimes as can be seen by decreased carbon monoxide concentrations in the flue gases.

Despite significantly lower fuel consumption during part load regimes in tests 6 and 7, the concentrations of emitted particles are close to those of the tests 4 and 5 . The lower temperatures and elevated concentrations of $\mathrm{CO}$, up to $1500 \mathrm{mg} / \mathrm{Nm}^{3}$ (at $13 \% \mathrm{O}_{2}$ ) during the combustion phase, indicate some deficiency of combustion process of this regime. 


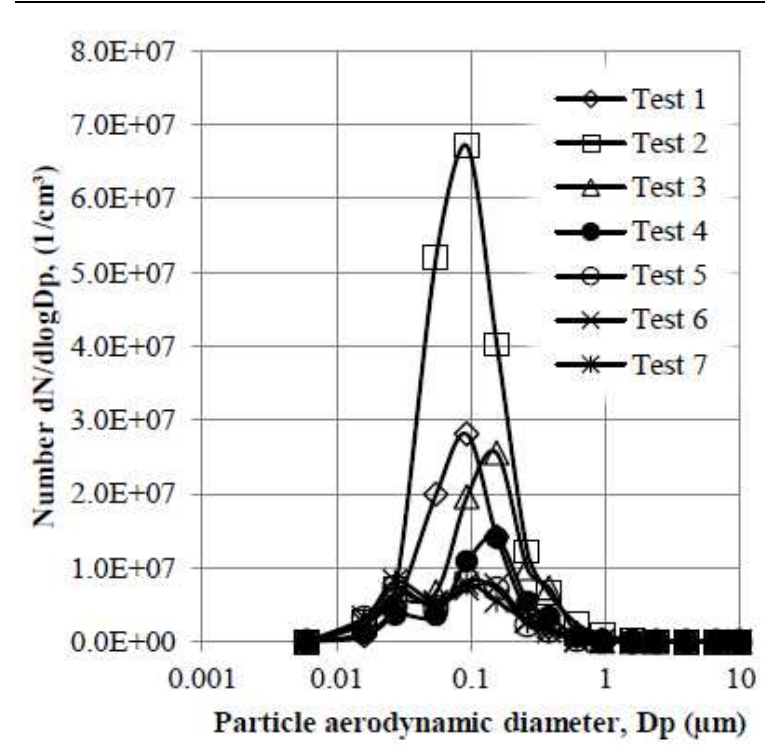

Fig. 4. Number size distribution obtained from burnout phase of different tests

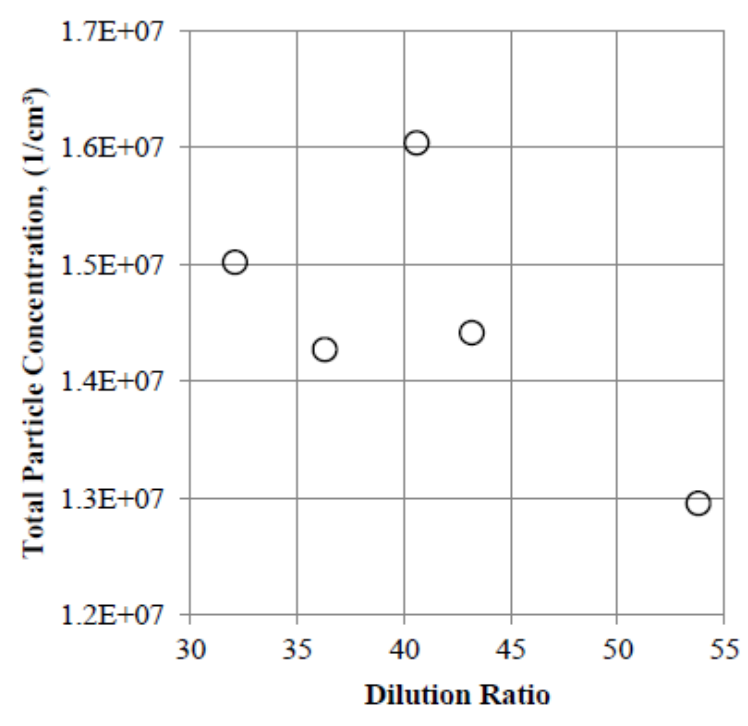

Fig. 5. Total particle concentrations measured at different dilution ratios

A burnout phase started by stopping the fuel feeding mechanism of the device. It is accompanied, as expected, by a sharp rise in carbon monoxide concentrations and could last up to one hour. The emissions however, as seen from Fig. 1, were occurring due to the glowing bed inside the combustion chamber. The particle emission steadily decreased over time. Particle size distributions for the burnout phase are shown in Fig. 4. Their multi-modal characters vary for different tests with the maximums shifted towards the vicinity of 21 and $39 \mathrm{~nm}$. Particle emission factors of Table 2 are represented for cases with and without taking into account the burnout phase. As can be seen the differences of the corresponding values are insignificant. Though, since the burnout phase usually lasts rather noticeable time period, about one hour or more, additional attention might be required to the introduced levels of emitted particles.

Some part of the test 4 was carried out to determine the influence of the dilution ratio on the particle concentrations. As can be seen from Fig. 5, the particle total concentrations of the test runs vary between $1.3 \times 10^{7}$ and $1.6 \times 10^{7} \mathrm{~cm}^{-3}$. As the standard deviation estimated for the combustion phase of this test is $1.9 \times 10^{7}$ $\mathrm{cm}^{-3}$, one may conclude that the dilution ratio does not have a visible impact on the measuring results, which corresponds the observations of Gaegauf and Griffin (2007) during the sampling the particle emission in the dilution tunnel.

\section{Conclusion}

Measurements of particle and gaseous emissions were carried out during the tests on a modern $5 \mathrm{Kw}$ pellet stove operating at nominal and part load regimes. The particle emission factors of the starting phase and combustion phase are within the range of $3.07 \times 10^{14}$ and $2.44 \times 10^{15}$ particles per $\mathrm{kg}\left(1.97 \times 10^{13}\right.$ and $1.57 \times 10^{14}$ particles per MJ). Taking into account the burnout phase does not introduce much difference to the emission factors, those values are within the range of $2.53 \times 10^{14}$ and $2.67 \times 10^{15}$ particles per $\mathrm{kg}\left(1.62 \times 10^{13}\right.$ and $1.71 \times 10^{14}$ particles per MJ). Results of particle emission obtained during the tests at part load regime are within the same range as for the nominal load regime. No dependence of the measured particle number concentrations on the dilution ratio is observed. The number concentration distributions of particles during the stable combustion are bimodal with the dominant mode of the fine particles. The results of this work are in general agreement with literature.

\section{Acknowledgement}

The authors are very thankful to Md. Obaidullah, Thomas Duquesne and Jean Dominique Thomassin for their assistance during the experiments. The financial support of the European Regional Development Fund (ERDF/EFRO), project no. P12-05 EMOVO is gratefully acknowledged.

\section{Author's Contributions}

Igor V. Dyakov: Planning, organising, conducting the experiment, data analysis and treatment, discussing and writing the article. 
Benjamin Bergmans: Organising the experiment, discussing and writing the article.

Svend Bram: Organising the experiment, discussing and writing the article.

Jacques De Ruyck: Organising the experiment.

Francesco Contino: Organising the experiment, data analysis and treatment, discussing and writing the article.

\section{Ethics}

This article is original and contains unpublished material. The corresponding author confirms that all of the other authors have read and approved the manuscript and no ethical issues involved.

\section{References}

Bari, M.A., G. Baumbach, J. Brodbeck, M. Struschka and B. Kuch et al., 2011. Characterisation of particulates and carcinogenic polycyclic aromatic hydrocarbons in wintertime wood-fired heating in residential areas. Atmospheric Environ., 45: 7627-7634. DOI: 10.1016/j.atmosenv.2010.11.053

Bølling, A.K., J. Pagels, K.E. Yttri, L. Barregard and G. Sallsten et al., 2009. Health effects of residential wood smoke particles: The importance of combustion conditions and physicochemical particle properties. Particle Fibre Toxicol., 6: 1-20.

DOI: $10.1186 / 1743-8977-6-29$

Boman, C., E. Pettersson, R. Westerholm, D. Boström and A. Nordin, 2011. Stove performance and emission characteristics in residential wood log and pellet combustion, part 1: Pellet stoves. Energy Fuels, 25: 307-314. DOI: 10.1021/ef100774x
EN 13284-1, 2002. Stationary source emissions. Determination of low range mass concentration of dust. Part 1: Manual gravimetric method; Belgian Bureau for Standardization.

$\mathrm{N}-14785$, 2006. Residential space heating appliances fired by wood pellets: Requirements and test methods. Belgian Standards Institute (NBI).

Gaegauf, C. and T. Griffin, 2007. University of Applied Science Bale/Muttenz. Comparison of in-stack and dilution tunnel measurement of particulate emission.

Sippula, O., 2010. Dissertation, Fine particle formation and emissions in biomass combustion. University of Eastern Finland, Kuopio, Finland.

Sippula, O., K. Hytönen, J. Tissari, T. Raunemaa and J. Jokiniemi, 2007. Effect of wood fuel on the emissions from a top-feed pellet stove. Energy Fuels, 21: 1151-1160. DOI: 10.1021/ef060286e

Tissari, J., J. Nuutinen, K. Hytönen, S. Tuomi and J. Kouki et al., 2003. Fine particle and CO emissions in an under-fed pellet burner. Proceedings of the 1st International Symposium on Incomplete Combustion, Nov. 9-11, Kuopio, Finland.

WHO, 2006. Air quality guidelines for particulate matter, ozone, nitrogen dioxide and sulphur dioxide, Global update 2005. World Health Organisation report. 